\title{
Study on Sedimentary Characteristics of Chang 9 Member of Triassic in Ordos Basin
}

\author{
Jingbiao Bai* \\ No.5 Oil Production Plant of Changqing Oilfield Branch of Petrochina, Xi'an, China
}

\begin{abstract}
The Triassic Yanchang Formation in the Ordos Basin is one of the main exploration targets. Based on the detailed exploration of the outcrop at the southern margin of the Ordos Basin, combined with previous results, a systematic analysis of lithology, rock assemblage, sedimentary facies characteristics and temporal evolution is carried out. The results show that the Changchang 9 oil-bearing group on the southern margin of the Ordos Basin can be divided into 9 lithofacies types, and three types of sedimentary facies, meandering river, meandering river delta, and braided river delta are developed. The meandering river facies develops riverbed retention deposits, beaches, and There are four types of microfacies in natural dikes and rupture fans. There are five types of microfacies in meandering river deltas: underwater distributary channels, underwater natural dikes, divert bays, estuary dams, and remote sand dams. Braided river deltas develop underwater distributary channels, There are two kinds of microfacies between distributary channels; the Chang 9 oilbearing group has a coarse-fine-coarse compound rhythm in the vertical direction; meandering river sand bodies and delta front sand bodies are the main places for oil and gas migration and accumulation.
\end{abstract}

\section{Introduction}

The Upper Triassic Yanchang Formation in the southern margin of the Ordos Basin is a key horizon for the exploration and development of the Changqing Oilfield. Its sedimentology research began in the 1970s. Due to the large scale of the sandbody's horizontal distribution, the vertical stacking of complex and diverse sedimentary facies belts Changes are rapid and there are few studies on geological outcrop profiles in the field. Many scholars have inconsistent understanding of the sedimentary system in the study area. They believe that lakes and delta deposits mainly develop, which can be further divided into four types of deposits: delta plains, delta fronts, shallow lakes, and deep lakes. Subfacies; Jiang Qi et al. believed that sandy clastic flow deposits developed in the southern Ordos Basin, not traction flow deposits. The scale of single-stage clastic flows is generally small, and the thickness of multi-layer clastic flows increases. Based on the outcrop profiles of Luhe Village in Luochuan County and Yijun Road Crossing in Jinsuoguan on the southern margin of the Ordos Basin, the Upper Triassic in the southern margin of the basin is discussed on the basis of lithofacies characteristics, sedimentary facies signs and sedimentary sequence analysis, combined with the regional geological background. Sedimentary facies distribution characteristics and distribution evolution law of the Chang 9 member of Yanchang Formation.

\section{Geological background}

The Ordos Basin is located in the west of the North China Platform. It is a multi-cycle sedimentary basin with stable subsidence and depression migration. The basin area is about $25 \times 105 \mathrm{~km} 2$. In the Late Triassic, the basin was affected by the Qinling Mountains to the southwest - The influence of compression strike-slip and edge thrust nappe caused by the Qilian Mountain orogen is steep in the southwest and gentle in the northeast. The study area is located on the southern margin of the Ordos Basin, with the north part of the northern Shaanxi slope in the southeast, the east part adjacent to the flexure belt in western Shanxi, and the south part of the northeastern part of the Weibei uplift.

From bottom to top, the Yanchang component consists of 10 oil-bearing groups, of which the Chang 10-Chang 9 oil-bearing group is the target horizon. The Chang 10 sedimentary period is the formation stage of the lake basin, which is mainly composed of flesh-red and gray-green medium-coarse feldspar sandstone with silty mudstone, with a deposition thickness of 210-350 m; the Chang 9 sedimentary period is the expansion period of the lake basin, and The underlying Chang 10 oil layer group is in integrated contact, with gray-green medium-fine sandstone intercalated with dark mudstone and silt fine sandstone deposits, with a deposition thickness of 80 to $110 \mathrm{~m}$. On the whole, the Upper Triassic Yanchang Formation in the Ordos Basin was formed in a complete cycle of the inland depression lake basin. The lake basin

\footnotetext{
* Corresponding author: bjb1_cq@petrochina.com.cn
} 
experienced four stages of initial subsidence, strong depression, rebound uplift, and shrinkage.

\section{Sedimentary characteristics}

Through detailed survey and comprehensive analysis of the outcrop profile in the field, the Chang 10-Chang 9 oilbearing group of the Yanchang Formation mainly developed sedimentary facies types such as meandering river, meandering river delta and braided river delta. Among them, the outcrop profile of Luhe Village in Luochuan County is located in the northeast of the study area, with meandering rivers and meandering river delta fronts mainly developed. The outcrop section of Jinsuoguan-Yijun intersection is located in the southwest of the study area, and mainly develops braided river delta front subfacies.

\subsection{Lithofacies}

Lithofacies reflects the strength and weakness of hydrodynamic conditions, transportation methods, and depositional mechanisms during sediment deposition, and is an important theoretical basis for dividing sedimentary facies. By summarizing the characteristics of the lithology, grain size and sedimentary structure of the outcrop profile in the study area, the following nine lithofacies types have been identified

\subsubsection{Positive-grained sequence bedding and gravel-bearing coarse sandstone facies (S-Gg)}

It often develops on the scouring surface of the river channel and is composed of sorted, rounded and medium coarse sandstone. A small amount of fine gravel can be seen at the bottom of the river channel. The hydrodynamic force gradually weakened.

\subsubsection{Trough-like cross-bedding medium-coarse sandstone facies (Sct)}

It often develops inside the river channel and is composed of well-sorted and well-rounded middle-coarse sandstone. The trough-like cross bedding has a large scale, and the laminae are parallel to the interface of the strata. The depression direction of the two is the same. Migrate and fill the deposited product.

\subsubsection{Sandstone facies in parallel bedding (Smh)}

It is composed of well-sorted and well-rounded middle sandstone with parallel bedding. It is a product under strong hydrodynamic conditions and is commonly found in shallow water sedimentary environments in river beaches and underwater distributary channels at the delta front.

\subsubsection{Massive bedding medium-fine sandstone facies $(\mathrm{Sm})$}

It is composed of gray medium-fine sandstone, which is uniform and massive as a whole. The sediments are rapidly accumulated, and it is too late to differentiate and form.

\subsubsection{Wedge-shaped cross-bedding sandstone facies (Sw)}

It is composed of well-sorted, well-rounded medium-fine sandstone, with wedge-shaped cross-bedding and obvious wedge-shaped changes in the thickness of the strata. It is common in the depositional environment of the estuary dam in the front edge of the meandering river delta.

\subsubsection{Inverse-granular sequence bedding sandstone facies (Sgi)}

It is composed of well-sorted and well-rounded dark gray medium-fine sandstone. The bottom is dominated by sedimentary fine sandstone, and it gradually transitions upward to medium sandstone. From bottom to top, the sediment grain size changes from fine to coarse, and the hydrodynamic conditions gradually increase, Is a typical symbol of estuary dams and remote sand dams.

\subsubsection{Massive bedding silt fine sandstone facies (Fm)}

It is composed of silt-fine sandstone that is sorted and well-rounded. It is uniform and massive as a whole without any laminar structure. It often appears in stable and low-energy hydrodynamic environments such as natural dikes and remote sand dams.

\subsubsection{Climbing sand grain bedding silt fine sandstone facies (Fr)}

The silt fine sandstone with climbing sand-line bedding is the product of wave-breaking migration. The hydrodynamic strength is relatively weak, and it often develops in the natural embankment environment on both sides of the river.

\subsubsection{Mudstone Facies (M)}

Mainly gray-green, gray-black massive mudstone and silty mudstone, with a thickness of 10 to $100 \mathrm{~cm}$, finegrained sediments suspended below the lake base level slowly accumulate vertically under low-energy static water conditions.

\subsection{Sedimentary facies}

\subsubsection{Meandering river facies}

The typical sand body is selected from the 10 oil layer group in the Luhe Village section of Luochuan County, about $65 \mathrm{~m}$ long and $12 \mathrm{~m}$ thick, with a large channel 
width-to-depth ratio and east-west trending. This set of sand bodies is a meandering river deposit. The channel sand bodies are composed of two-stage channel units. The thickness of the single-stage channel sand bodies is 2-6 m, and the appearance is similar to the top flat bottom concave shape. Macroscopically, meandering river sediments have an obvious "dual structure", and the grain size of sediments gradually becomes finer from bottom to top, which is a positive-grained sequence bedding. Among them, channel unit I is relatively complete, from bottom riverbed sedimentation $\rightarrow$ side beach $\rightarrow$ natural embankment $\rightarrow$ burst fan and other vertical superimposition. The typical lithofacies sequence is S-Gg $\rightarrow \mathrm{Sct} \rightarrow \mathrm{Smh} \rightarrow \mathrm{Fm} \rightarrow \mathrm{Sm}$; channel unit II Remaining sediments from the bottom riverbed

$\rightarrow$ Boundary beach $\rightarrow$ Natural dike vertical stacking or directly from the beach $\rightarrow$ Natural dike group

The typical lithofacies sequence is $\mathrm{S}-\mathrm{Gg} \rightarrow \mathrm{Sct} \rightarrow \mathrm{Smh} \rightarrow$ $\mathrm{Fm}$ or $\mathrm{Smh} \rightarrow \mathrm{Fm}$. The river channel unit I was formed with a large curvature. Later, due to the event of flooding, a new river bed was scoured along the direction of the convex bank by the gully, which straightened the river channel, causing the "string gully straightening" effect, and then the channel unit II was formed. On the basis of previous studies on meandering rivers, perfect and establish a model.

\subsubsection{The meandering river delta facies}

The typical sand body is selected from the Chang 9 oil layer group in the Luhe Village section of Luhe Village, Luochuan County, north-east of the study area, with a length of about $60 \mathrm{~m}$, a thickness of about $17 \mathrm{~m}$, and an east-west strike. Through a comprehensive analysis of the rock types, sedimentary structures, and lithofacies combination of the outcrop section, it is believed that this set of sand bodies belongs to the sub-facies deposition of the meandering river delta front, which is probably formed by the vertical superimposition of 13 stages of underwater channel units. The thickness of the singlestage channel unit is 0.3 to $3 \mathrm{~m}$, and the lateral migration range is relatively large. The sand body deposits are thicker near the main channel, and the sand body deposits are significantly thinner away from the main channel, and the appearance is approximately Lens-like form. At the bottom of the outcrop profile, the grain size of the sediment gradually thickens upwards, that is, the typical inverse granular bedding, which belongs to the estuary bar sediment. The typical lithofacies sequence is $\mathrm{Sgi} \rightarrow \mathrm{Sw}$. River course

$\rightarrow$ Underwater natural dike or underwater distributary channel $\rightarrow$ Underwater natural dike $\rightarrow$ Vertical stacking of diversion bays, gradually narrowing grain size from bottom to top, the typical lithofacies sequence is $\mathrm{Sct} \rightarrow \mathrm{Fr}$ or $\mathrm{Sct} \rightarrow \mathrm{Fm} \rightarrow \mathrm{M}$; in the outcrop section On the upper part, it gradually transitions from far sand dam $\rightarrow$ estuary dam $\rightarrow$ underwater distributary channel $\rightarrow$ underwater natural embankment or directly superimposes from far sand dam $\rightarrow$ estuary dam. The sediment grain size of the former is fine $\rightarrow$ coarse $\rightarrow$ fine composite from bottom to top Rhythm, the latter is directly composed of fine-grained anti-granular bedding. The typical lithofacies sequence is $\mathrm{Sm} \rightarrow \mathrm{Sgi} \rightarrow \mathrm{Sw} \rightarrow \mathrm{Sct} \rightarrow \mathrm{Fm}$ or $\mathrm{Sm} \rightarrow \mathrm{Sgi} \rightarrow \mathrm{Sw}$. Compared with braided river deltas, meandering river delta fronts have the characteristics of complete facies belt development, diverse rhythm types, and rich lithofacies assemblage sequences.

\subsubsection{Braided river delta facies}

The typical sand body is selected from the Chang 9-Chang 8 oil layer group at the outcrop section of the south west Jinsuoguan Yijun road. The interface between Chang 9 and Chang 8 can be clearly seen on the outcrop section, and the distribution types of the two sand bodies are significantly different. The channel of Chang 9 oilbearing group is east-west, about $75 \mathrm{~m}$ long and $15 \mathrm{~m}$ thick. The channel has a large width-to-depth ratio, coarser sediment grain size, and lower sandstone component maturity and structural maturity than meandering river deltas. Due to the relatively steep paleotopography, along with the rise of the lake level, sedimentation was formed under the background of lake transgression. The exposed sand bodies belonged to the front subfacies of braided river delta, and the positive rhythm channel sand bodies superimposed vertically in multiple stages developed. It can be seen that the scouring surface, the channel undercutting and eroding the channel sand body of the previous stage, and the development of trough-shaped cross bedding and parallel bedding, reflecting the multiple underwater distributary channels in the front of braided river delta under strong hydrodynamic force The deposition process of migration, scouring and stacking. In addition, in the eastern part of the outcrop section, a thin layer of dark oil shale with a thickness of about 0.3 to $0.5 \mathrm{~m}$ was deposited in the late Chang 9 oil layer group, commonly known as "Lijiapan Shale". The 12-stage underwater channel unit is superimposed in the vertical direction. The thickness of the single-stage channel unit is 0.3 to $25 \mathrm{~m}$. The lateral migration range is smaller than that of the meandering river delta, and the sediment grain size is larger than that of the meandering river delta. Since the southwest outcrop profile is relatively close to the provenance area and is often modified by waves and bank currents, the braided river delta has the characteristics of incomplete facies belt development. The outcrop profile does not develop estuary dams and remote sand dam deposits. The microfacies between underwater distributary channels and distributary channels are developed.

\section{Sedimentary evolution characteristics}

During the period of the Upper Triassic Yanchang Formation, the Ordos Basin was affected by the Indosinian movement, forming a large asymmetrical skipshaped foreland basin with a steep southwest and a gentle northeast. It has the characteristics of multiple water systems, multiple provenances, and sufficient supply of provenance. . The two major provenance systems of 
southwest and northeast directions bring a large amount of clastic sediments, which are the deposits of the braided river delta at the Jinsuoguan-Yijun intersection in the southwest direction of the study area and the meandering river and meandering river delta of Luhe Village in Luochuan County from the northeast direction. The system provides the material basis. In this context, the Chang 10-Chang 9 oil layer group of the Yanchang Formation in the southern margin of the Ordos Basin mainly developed sedimentary facies types such as meandering river, meandering river delta, and braided river delta.

In the early depositional period of the Yanchang Formation (the period of the Chang 10 oil layer formation), the orogenic belt in the southwestern margin of the basin was not uplifted high, and no large-scale thrusting occurred. A set of meandering river deposits was deposited in the background. During the middle depositional period of the Yanchang Formation (the depositional period of the Chang 9 oil-bearing group), due to the influence of the Indosinian movement, the orogenic belt on the southwestern margin of the basin quickly uplifted and began to undergo large-scale thrusting. The topography has steep slopes and abundant sediment supply. The subsidence rate of the southwestern margin has accelerated. The frontal outcrop profile of the braided river delta at the south-west direction of Jinsuoguan-Yijun intersection in the study area was formed during this thrust load settlement process. In the study area from the northeast to the outcrop profile of Luhe Village in Luochuan County, the basin as a whole was compressed and depressed, and the climate changed from arid and rainless (Chang 10 layer deposition period) to humid and rainy (Chang 9 layer deposition period), Leading to a significant increase in the base level. The base level was in the low-stand system tract period in the early stage (the Chang 10 layer group deposition period), and meandering river deposits developed. Later (the Chang 9-layer group deposition period) the base level rose, reforming the lowstand stage sedimentation and causing diversion. Channel sand bodies regressed towards the land, forming meandering river delta deposits.

Looking at the sedimentary microfacies and lithofacies types of the Chang 10-Chang 9 oil-bearing group in the southern margin of the Ordos Basin, it can be seen that the vertical sedimentary sequence has obvious compound rhythm characteristics. From the perspective of sedimentary microfacies, from bottom to top, the riverbed sediments, beaches, natural dikes, and rupture fans of meandering rivers are transformed into remote sand dams, estuary dams, and underwater distributary channels on the delta front. From the perspective of lithofacies, the pebbly coarse sandstone facies of the trough-shaped crossbedding and the positive-grained sequence bedding, which indicate strong hydrodynamics, transition upwards to the massive bedding medium-fine sandstone facies, and then upwards become the interaction between rivers and lakes. Wedge-shaped cross-bedding and anti-granular bedding medium-coarse sandstone facies formed by the action. On the whole, it is a set of coarse-fine-coarse composite rhythm sand bodies, reflecting the result of the base level rising and sand body degrading.

\section{Conclusion}

(1) A total of 9 lithofacies types have been identified in the outcrop profile in the wild, and three sedimentary facies types: meandering river, meandering river delta and braided river delta are developed.

(2) During the deposition period of Chang 9 oil layer group, the northeastern area of the study area transitioned from meandering river facies to meandering river delta facies, which was inherited sedimentation; during the deposition period of Chang 9 oil layer group, the sedimentary facies changed from the southwest to northeast of the study area. The river delta turns into a meandering river delta, with obvious differences in sedimentary facies; the Chang 9 oil-bearing group has a coarse-fine-coarse compound rhythm in the vertical direction.

(3) Meandering river sands and delta front sands are important places for oil and gas migration and accumulation. The muddy sediments on the delta front can be used as a cover layer for oil and gas accumulation and form a favorable reservoir-caprock combination in the vertical direction, which is an important place for oil and gas exploration, it's the favorable zone.

\section{References}

1. The Influence of Reservoir Heterogeneity on Oilfield Development Effect[J]. Xu Jianhong, Qian Lidan,Kurban. Fault Block Oil and Gas Field. 2017(05).

2. The influence of reservoir heterogeneity on the degree of oil and gas enrichment[J]. Li Jinpeng. Inner Mongolia Petrochemical Industry. 2017(06).

3. Delta deposition and evolution of the Upper Triassic Yanchang Formation in the Ordos Basin[J]. Wu Fuli, $\mathrm{Li}$ Wenhou, Li Yuhong, Xi Shengli. Journal of Palaeogeography. 2014(03).

4. Analysis of control factors of ultra-low porosity and permeability sandstone reservoirs of Yanchang Formation in Fuxian County, Northern Shaanxi[J]. Li Chunyu, Xie Yuan, Liu Shaoguang, Huang Hongwei, Li Minghui. Journal of Chengdu University of Technology. 2012(03).

5. Accumulation conditions and characteristics of Nanniwan Oilfield[J]. Ji Yongtao, Liu Jianhong. Northwest Geology. 2012(02).

6. Sequence stratigraphic division and hydrocarbonbearing properties of Yanchang Formation in northern Shaanxi[J]. Yang Lei, Mei Zhichao, Xiong Wei. Journal of Palaeogeography. 2021(03).

7. Discussion on sedimentary characteristics and provenance of Yanchang Formation in southern Ordos Basin[J]. Lin Hongbin, Yao Jingli. Journal of Xi'an Petroleum Institute (Natural Science Edition). 2020(05).

8. Reservoir characteristics and oil displacement efficiency analysis of Chang 6 reservoir in Pingqiao area and Wangyao area of Ansai Oilfield[J]. Zhu 
Yushuang, Qu Zhihao, Kong Lingrong, Chen Rong, Li Jinfeng. Acta Sedimentologica Sinica. 2020(02).

9. A preliminary study on the law of oil and gas enrichment in Nanniwan Oilfield[J]. Dong Yilong, Wang Weixi, Liu Jianhong. Natural Gas Geoscience. 1998(02).

10. Sedimentary facies characteristics and storage conditions of Chang 6 reservoir group in Chuankou Oilfield[J]. Li Wenhou, Liu Yiqun, Feng Qiao. Journal of Northwest University (Natural Science Edition). 1996(02). 